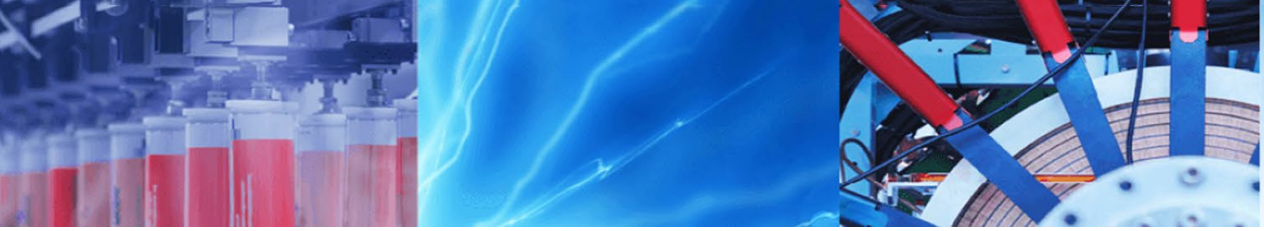

Research Article

\title{
A study of the parameters that determine the reactivity of sugarcane bagasse ashes (SCBA) for use as a binder in construction
}

\author{
R. Lima Figueiredo ${ }^{1} \cdot$ S. Pavía ${ }^{1}$ (D)
}

Received: 6 April 2020 / Accepted: 17 July 2020 / Published online: 14 August 2020

(c) Springer Nature Switzerland AG 2020

\begin{abstract}
This paper intends to contribute to the use of waste, as binder replacement, to lower the negative environmental impact of construction. Sugarcane bagasse ash (SCBA) is an agricultural waste which has been reported as pozzolanic. However, the literature on the pozzolanic activity of SCBA is inconclusive. This paper attempts to establish the properties that determine reactivity the most, in an effort to standardise the material, to allow a wider intake into mainstream construction. The fineness, specific surface area, microstructure, composition and amorphousness of ashes from four producers in Brazil are studied, and the microstructure and kinetics of reactions in ash/hydrated-lime pastes investigated with SEM/EDS. The results evidence that, despite their high crystallinity and carbon content, the ashes are pozzolanic. Reactivity was proven with physical (activity index) and chemical tests (conductivity), and hydrates were evident at 7 days. Reactivity increased with rising specific surface area, amorphousness and fineness, but the specific surface area of the particles impacts reactivity the most. This was concluded form the following findings: Fineness is not vital for reactivity, as some coarse ashes produce similar strengths and combine comparable amounts of lime than much finer ashes. The presence of a significant amorphous fraction is not vital for reactivity, as the ashes are active despite consisting mostly of crystalline phases (quartz, corundum and hematite). High carbon contents do not eradicate reactivity, as the ashes with the greatest carbon are the most reactive, achieving the highest strengths and combining the most lime. Finally, all the SCB ashes present a marginal content of anions and alkalis capable of forming detrimental gels and salts, a desirable quality for any pozzolanic material.
\end{abstract}

Keywords Sugarcane bagasse ash · Reactivity · Specific surface area · Amorphousness · Fineness · Carbon content

\section{Introduction}

Today, traditional binders are often partially replaced by pozzolans and supplementary cementitious materials (SCMs), some of them waste, to produce materials of lower embodied energy and lower $\mathrm{CO}_{2}$ emissions and reduce the negative environmental impact of construction. This also carries economic benefits as it lowers the cost of raw materials, and the amount of landfill waste and quarrying, hence contributing to the preservation of natural resources [1, 2]. Most of the 27 members of the family of cements in EN 197-1 [3] include either SCMs or pozzolans; CEM I is the only cement consisting nearly entirely of clinker (calcium silicates). The use of SCMs and pozzolans is escalating. In 2011, the European cement industry used 47.8 million tons of alternative raw materials in cement production [4]. In 2006, the amount of CEM I in the CEMBUREAU countries was $28 \%$ of the total cement production, while blended cements corresponded to $72 \%$ [5]. It is estimated that the production of blended cements has a global potential for reducing cement-making $\mathrm{CO}_{2}$ emission of at least $5 \%$ and up to $20 \%$ [6].

S. Pavía, pavias@tcd.ie; R. Lima Figueiredo, limafigr@tcd.ie| 'Department of Civil, Structural and Environmental Engineering, Trinity College Dublin, Dublin, Ireland. 
Sugarcane bagasse ash (SCBA) is a by-product of the sugar/ethanol agroindustry. Brazil leads the world production of sugarcane, harvesting around 633.26 million tons per year [7]. The ashes used in this research originate from four sugarcane industries in São Paulo which in 2019 processed c. $55 \%$ of the total sugarcane produced in Brazil [7]. After milling the sugarcane to extract the juice, the bagasse is transported to a boiler where it is burned to produce steam and electricity. The boiling temperature can vary remarkably, from $700^{\circ} \mathrm{C}$ reaching up to $1000^{\circ} \mathrm{C}$ [8-10]. The burning of the bagasse leaves approximately $0.3 \%$ of ash residue [11]. The ash can be rich in reactive silica and has pozzolanic potential.

Pozzolanic reaction has been investigated for decades and is mainly governed by the amorphous silica and alumina contents and the specific surface of the pozzolan. Initially, a high specific surface enhances pozzolanic reaction but, at later ages, it is essentially controlled by the active silica and alumina content [12]. It is generally accepted that the silica and alumina must be in amorphous form to be active; hence amorphous pozzolans are considered active, while pozzolans with a significant crystalline fraction and low glass content are assumed to have weak activity. Walker and Pavia [13\} state that amorphousness determines pozzolan reactivity to a greater extent than any other property (testing ceramics, fly ash, GGBS, kaolin, microsilica and others). However, despite the general assumption that the crystalline fraction is non-reactive, some crystalline minerals can bind lime [12, 14-16]; hence, the amount of lime bound by a pozzolan's crystalline fraction can be underestimated.

Most authors agree that SCBAs are pozzolanic [17]. Torres et al. [18] found that the pozzolanic activity index of a SCBA with significant amorphous content exceeded the minimum ASTM C618 requirement. However, De Soares et al. [19] claim that SCBA has low or no reactivity, and that it should be used as an inert replacement. This was already reported, in 1998, by Martirena-Hernandez et al. [20], who remark that SCBA is not reactive, mainly due to the presence of unburned material and carbon. However, they detected CSH at 7 days in lime/SCBA pastes.

Residual carbon in pozzolans absorbs moisture and can lower reactivity and spoil the rheology of the materials, increasing the water demand for a given consistency. SCBA typically contains carbon residues from the original sugar bagasse, and some authors have attempted to rid of this carbon by calcination to enhance pozzolanic activity [21-23]. In contrast, other authors claim that a high carbon content does not adversely affect reactivity. Chusilp et al. [24] demonstrated that even though, at early ages, carbon content $(>10 \%)$ lowers early strength, at later ages ( 28 days), $20 \%$ carbon content provides compressive strengths similar to the control mix.
The effect of the alkali content on the reactivity of the ashes has not yet been investigated. Alkalis can speed up the dissolution of the amorphous silica favouring early pozzolanic reaction; however, when present in the pore solution at later ages, they adversely affect durability due to alkali-silica reaction. Shi and Day [25] examined the effect of activators $\left(\mathrm{Na}_{2} \mathrm{SO}_{4}\right.$ and $\left.\mathrm{CaCl}_{2}\right)$ on pozzolanic reaction kinetics, concluding that the addition of $4 \%$ $\mathrm{Na}_{2} \mathrm{SO}_{4}$ increased both the early and later strengths while $4 \% \mathrm{CaCl}_{2} \cdot 2 \mathrm{H}_{2} \mathrm{O}$ lowered early strength but increased late strength.

Research results on the pozzolanic activity of SCBA agree with the general parameters that govern pozzolanic activity presented above. Cordeiro et al. [26] evidenced that the finest SCBA provided the highest pozzolanic activity and density, producing a higher compressive strength, while Cordeiro and Kurtis [11] evidenced that increasing the SCBA's specific surface area enhanced pozzolanic activity and strength, and that early hydration increases with decreasing SCBA particle size. They found a direct linear relationship between strength and specific surface area, with correlation coefficients higher than $94 \%$. They also claim that coarser ashes (D50 c.30 $\mu \mathrm{m}$ ) behave as inert mineral additions.

One of the main tests to determine pozzolanic activity is to measure the strength of pozzolan composites compared to a reference material (mechanical index). The pozzolanic reaction is slow; hence, pozzolans may not increase early strength but can significantly increase ultimate strength [12]. This has been confirmed for SCBAs: ArenasPiedrahita et al. [27] found that 10-20\% SCBA decreased compressive strength at early ages but, after 90 days, the strength was similar or surpassed the control sample. Furthermore, strength development in pozzolanic materials not only relates to the evolution of the pozzolanic reaction (amount of combined lime and hydrates formed), but also to the physical filler effect of the pozzolans that increases density and strength and is enhanced by the presence of finer particles. The filler effect of the non-reactive part of the SCBAs is also noted in the literature $[11,19]$.

Previous authors have investigated the reactivity of SCBA in Portland cement (PC) systems. Some authors report that $20-30 \%$ of cement can be replaced with SCBA without prejudice to strength $[18,28,29]$ or even a strength increase $[24,30]$. Some authors set the optimum replacement of PC with SCBA in concrete at $20 \%$ [31] others at $15 \%[32]$ and others even lower, at $10 \%[33,34]$ or $5 \%[35,36]$.

As it can be seen from the literature, the results are inconsistent, with lack of agreement on the SCBA reactivity and ample variability on the optimal substituion of binder with SCBA. The disparity of the results suggests that the nature of the ashes significantly determines the 
properties of the composites. SCBA is a natural material and, as such, it is subject to variability. Sales and Lima [37] note that some SCBAs have poor reactivity due to the lack of control on the production parameters, and this restricts use. In addition, the presence of contaminants and varying burning conditions result in SCBAs with different chemical composition and reactivity. Hence, it is fundamental that individual sources of SCBA are evaluated. This paper investigates the properties and reactivity of four ashes. It intends to contribute to the existing knowledge of SCBA ashes to enhance their use in construction. It also attempts to determine which of the SCBA properties determine reactivity the most, in an effort to standardise the material and allow a wide intake into mainstream construction.

\section{Materials and methods}

A hydrated lime (CL90-S) complying with EN 459-1 [38] and a siliceous sand of grading and composition complying with the European standards were used. The ashes were sourced from four Brazilian sugarcane industries. The raw SCBAs were oven-dried at $105^{\circ} \mathrm{C}$ for $24 \mathrm{~h}$. Grinding was then performed to enhance fineness using a TEMA T100 Disc Mill (1000 RpM; max sample $150 \mathrm{~g}$ ). As relatively small quantities are required for analysis and testing, homogenisation was ensured by subsampling, using a Rotary Sample Divider laborette 27 , to ensure representativity.

\subsection{Grading, specific surface area and microstructure}

The particle size distribution was measured by laser diffraction using a Mastersizer 2000, composed of three units, the Mastersizer 2000 unit; the Hydro 2000G wet dispersion unit; and the Autosampler 2000. Laser diffraction measures the angular distribution and intensity of the light by particles in suspension and uses the Mie theory of diffraction to process the results. Lime was included as a control material to which compares the grading of the ashes. The solubility of lime in water is ignored in the calculations, as it is very low at room temperature, and the measurement was carried out instantaneously on dispersion. The specific surface area of the particles was determined with a Quantachrome Nova 4200e and the BET method, a model isotherm based on adsorption of nitrogen gas on a surface. The microstructure of the ashes was analyzed with a scanning electron microscope (SEM), Tescan Mira XMU, revealing the surface topography, morphology and pore system with a backscattered electron (BE) signal detector.

\subsection{Chemical composition, mineral composition and amorphousness}

The chemical analysis as percentage by oxides was performed by Inductively Coupled Plasma-Atomic Emission Spectroscopy (ICP-AES) analysis. Oxide concentration was calculated from the determined elemental concentration. The carbon content was determined by thermal decomposition using the loss on ignition (LOI) method. The carbon was calculated from the difference in weight at a set temperature. The mineralogical composition and amorphous character of the ashes were analysed by X-Ray Diffraction (XRD), using a Phillips PW1720 XRD with a PW1050/80 goniometer and a PW3313/20 Cu k-alpha anode tube at $40 \mathrm{kV}$ and $20 \mathrm{~mA}$. All measurements were taken from $3^{\circ}$ to $60^{\circ}(2 \theta)$ at a step size of $0.02^{\circ} / \mathrm{s}$.

\subsection{Reactivity by electrical conductivity}

The conductivity variation of lime-ash suspensions over time was monitored to assess the ability of the ashes to combine lime- $\mathrm{Ca}(\mathrm{OH})_{2}$-and thus their reactivity according to de Luxan et al. [39]. A sample $(0.8 \mathrm{~g})$ of ash was added to a saturated hydrated-lime solution $(0.2 \mathrm{~g}$ of lime in $100 \mathrm{~mL}$ of water). The solutions were kept in sealed flasks to avoid evaporation and carbonation. A thermostatic bath was used to maintain the flasks at constant temperature $\left(20^{\circ} \mathrm{C}\right)$. The loss in conductivity was measured at intervals over $168 \mathrm{~h}$ using a WTW Conductivity Meter ProfiLine Cond 197i.

The conductivity loss (\%) was calculated according to the following equation:

$C(\%)=\frac{C_{i}-C_{t}}{C_{i}} \times 100$

where $C_{i}$ is the initial electrical conductivity of a $\mathrm{Ca}(\mathrm{OH})_{2}$ suspension before adding the ash; $C_{t}$ is the electrical conductivity of the ash and lime suspension measured at time intervals.

\subsection{Reactivity by strength development}

The pozzolanic activity of the ashes was measured by monitoring strength development according to EN 450-1 [40]. The mechanical index was calculated as the ratio of the compressive strength of the ash specimens to a standard lime mix. $40 \times 40 \times 160 \mathrm{~mm}$ prisms were produced with a ratio by mass of 1:1:3:2 (lime: SCBA:sand: water) for SCBA 1 and SCBA 2; and a slightly lower water content (1:1:3:1.5) for SCBA 3 and SCBA 4. The water content was lower in order to meet the lower water demand of the ash 
which was determined according to the research results and equation in Walker and Pavia [41]. The 1:1 (lime:ash) content was chosen to be able to compare with former literature $[13,17,41]$. The specimens were demolded after 3 days and cured for 90 days at $20^{\circ} \mathrm{C}$ and $60 \%$ relative humidity. The flexural strength was assessed following EN 196-1 [42].

The activity index (mechanical index) is adopted from EN450-1-fly ash (FA) for concrete. In this standard, the activity index is the ratio (in percentage) of the compressive strength of standard mortar bars prepared with $75 \%$ test cement and $25 \%$ fly ash (by mass) to the compressive strength of the standard bars prepared with $100 \%$ cement. The FA standard limit value for the activity index (single results) is $70 \%$ at 28 days. To investigate the SCBAs, we have adopted the same method. However, we cannot compare the results nor apply the standard limits as we are not using cement but lime, and furthermore, we are using waste of lower activity.

\subsection{Microstructure and kinetics of reaction of sugar bagasse ash/hydrated-lime pastes}

Pastes were fabricated with each of the ashes and hydrated lime (CL90-S) at 1:1 ratio by weight. The pastes were studied with a SEM/EDS system. The study focussed on the quality and quantity of pozzolanic hydrates at 7 and 28 days, and the microstructure of the pastes. In the pastes, the reaction between hydrous silica and lime should produce $\mathrm{C}-\mathrm{S}-\mathrm{H}$. As this reaction has a varying stoichiometry, the calcium/silicate $(\mathrm{C} / \mathrm{S})$ ratios of the $\mathrm{C}-\mathrm{S}-\mathrm{H}$ product were measured and compared with results in the literature. The SEM imaging results are qualitative; therefore, the quantification of the mineral phases was carried out by EDS and XRD. The XRD results were quantified using the refractive indices of the minerals, the relative intensity (\%) and the area of the peaks in the XRD trace. Also, the chemical composition of mineral phases in the lime paste was determined by SEM/EDS according to their relative proportions and $\mathrm{C} / \mathrm{S}$ ratio.

\section{Results}

\subsection{Grading, specific surface area and microstructure}

According to the particle size distribution (Fig. 1 and Table 1), SCBA 1 and SCBA 2 are the finest ashes. They present similar curves, with $90 \%$ of the particle volume under $29.7 \mu \mathrm{m}$ and $33.03 \mu \mathrm{m}$ respectively, well under the particle size of the hydrated lime with $90 \%$ of particles under $57.98 \mu \mathrm{m}$. The SCBA 3 and SCBA 4 ashes are much coarser

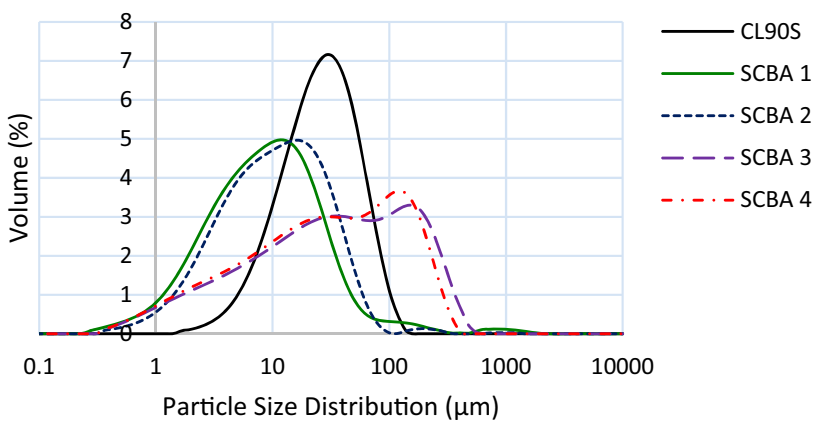

Fig. 1 Grading of the ashes by laser diffraction

and exhibit a broader range of particle sizes. As it can be seen from the laser grading, in all the ashes, over $75 \%$ of the particle volume falls into the hydrated-lime particle range (1.44-138.04 $\mu \mathrm{m})$-above 92\% for SCBA 1 and SCBA 2. According to the D50 parameter (median diameter or medium value of particle size distribution), SCBA 1 is the finest ( $D 50=8.14 \mu \mathrm{m}-50 \%$ of the particles in the sample are larger than $8.14 \mu \mathrm{m}$, and 50\% smaller) and SCBA 3 the coarsest (D50 $=31.26 \mu \mathrm{m})$.

In cement technology, it is considered that particles larger than $45 \mu \mathrm{m}$ are difficult to hydrate and those larger than $75 \mu \mathrm{m}$ seldom hydrate entirely [43]. The cumulative volume shows that less than only $7 \%$ of particles are greater than $45 \mu \mathrm{m}$ in the SCBAs 1 and 2 ashes, as opposed to a much higher percentage (42-45\%) in the SCBA 3 and 4.

The specific surface area of the ashes (Table 1) agrees with the particle size distribution, since the smaller the particle size the greater the specific surface area. However, the great disparity in the results (the SCBA 1 and SCBA 2 ashes present much greater specific surface area than SCBA 3 and SCBA 4) suggests a porous character for the SCBA 1 and SCBA 2 ashes. It is likely that the high carbon content of the SCBA 1 and 2 ashes has contributed to their high specific surface and has also enhanced their porosity. The SCBAs 1 and 2 ashes show specific surface areas greater than typical pozzolanic materials such as rice husk ash (RHA) and microsilica $\left(13.7 \mathrm{~m}^{2} / \mathrm{g}\right.$ and $\left.26 \mathrm{~m}^{2} / \mathrm{g}\right)[41,44]$. The $D$ values rate SCBA 1 as the finest; however, the SCBA 2 has a much greater surface area indicating that SCBA2 is the most porous among all the ashes.

The SEM analyses showed that the ashes contain an heterogeneous mixture of irregular, spherical, prismatic and flaky particles (Fig. 2) which agrees with other authors [17, 23 , 37]. In the SCBA 1 and SCBA 2 ashes, residual organic matter is evident as fibres and tabular particles, and cavities are filled with small particles which increases surface area (Fig. 2a-d). The SCBA 3 and SCBA 4 ashes contain more abundant coarse quartz than the other ashes (Fig. 2e, 
Table 1 Analyses of laser grading results, percentage of particles that determine reactivity and specific surface area of the ashes

\begin{tabular}{llccccc}
\hline & D10 $(\mu \mathrm{m})$ & $\mathrm{D} 50(\mu \mathrm{m})$ & $\mathrm{D} 90(\mu \mathrm{m})$ & $\%>45 \mu \mathrm{m}$ & $\%>75 \mu \mathrm{m}$ & $\begin{array}{l}\text { Specific } \\
\text { surface area } \\
\left(\mathrm{m}^{2} / \mathrm{g}\right)\end{array}$ \\
\hline SCBA 1 & 1.82 & 8.14 & 29.68 & 6.19 & 3.35 & 25.639 \\
SCBA 2 & 2.29 & 9.88 & 33.03 & 6.19 & 1.18 & 78.337 \\
SCBA 3 & 2.54 & 31.26 & 190.50 & 44.72 & 32.96 & 0.514 \\
SCBA 4 & 2.39 & 28.13 & 154.65 & 42.50 & 30.41 & 2.199 \\
CL90-S & 8.15 & 24.13 & 57.98 & 24.69 & 5.47 & 16.09 \\
\hline
\end{tabular}

f), and the quartz is often covered with agglomerates of fine spherical, flaky and needle-shaped particles. The SCBA 1 and SCBA 2 particles are finer and more porous, agreeing with the laser grading and specific surface area results.

\subsection{Chemical composition, mineral composition and amorphousness}

As it can be seen from Table 2, the chemical composition of the SCBA ashes compares well with others previously studied $[4-6,27]$. They include abundant silica $\left(\mathrm{SiO}_{2}\right)$ agreeing with previous authors. According to Cordeiro and Kurtis [6], silica is the main component of SCBA and arises from the original hydrated silica $\left(\mathrm{SiO}_{2} \cdot \mathrm{nH}_{2} \mathrm{O}\right)$ skeleton of the plant and soil contamination.

There are large discrepancies in the amount of $\mathrm{SiO}_{2}$ in the ashes from the four different providers (Table 2): the SCBA 3 and SCBA 4 ashes are the most siliceous $\left(\mathrm{SiO}_{2}>90 \%\right.$ by mass) while SCBA 1 and SCBA 2 ashes only contain 39 and $59 \%$, respectively. As it can be seen in Table 3 , the silica in SCBA 3 and 4 is crystalline quartz. Therefore, it is attributed to contamination, by sand attached to the sugarcane either during harvesting or later in the soil, as reported by previous authors $[6,12]$. The low carbon content of SCBA 3 and 4 agrees with this. Hence, the SCBA 1 and 2 providers probably collected the ash from the incineration chamber while the SCBA3 and 4 providers collected it from dumping sites.

The active alumina content also contributes to pozzolanic activity forming calcium aluminate hydrates ( $\mathrm{C}-\mathrm{A}-\mathrm{S}-\mathrm{H}$ and $\mathrm{C}-\mathrm{A}-\mathrm{H})$, also, aluminium can replace silicon in the $\mathrm{C}-\mathrm{S}-\mathrm{H}$ structure. The aluminium content in the ashes varies considerably, with SCBA1 showing the highest content at $13 \%$ and SCBA3 and 4 the lowest at 0.74 and 1.69 , respectively.

The XRD results were quantified using the refractive indices of the minerals, the relative intensity (\%) and the area of the peaks in the XRD trace (Table 3). The results (Fig. 3 and Table 3 ) indicate that the silica is mostly crystalline quartz, and the aluminium is mainly present as corundum $\left(\mathrm{Al}_{2} \mathrm{O}_{3}\right)$. Corundum is stable at high temperatures and, in small quantities, it doesn't significantly influence long-term pozzolanic activity [45]. It seems from the results that no metallic aluminium (which can cause expansion in an alkaline solution during setting) is present in the ashes [29]. Calcite peaks were only identified in SCBA 1 (Fig. 3a) agreeing with the chemical composition results (highest $\mathrm{CaO}$ of all ashes at $3.19 \%$ ). No calcite appears in the SCBA 2 trace (Fig. $3 \mathrm{~b})$ despite its calcium content $(\mathrm{CaO}=2.42 \%)$, probably due to being under the XRD detection limit (5\%). The XRD patterns of ashes SCBA 3 and 4 are nearly identical and highly crystalline, showing only quartz and minor hematite (Figs. $3 \mathrm{C}$ and $3 \mathrm{~d}$ ). SCBA1 has the highest iron content $(11.40 \%$ ) (Table 2 ) which is minor in the other ashes at c. $2 \%$. The mineralogical analyses (Table 3 ) indicate that the iron is present as crystalline hematite $\left(\mathrm{Fe}_{2} \mathrm{O}_{3}\right)$. Due to the low solubility and slow dissolution kinetics of hematite, it is likely that this iron does not contribute or contributes faintly to the pozzolanic reaction.

The SCBA 1 and SCBA 2 ashes present high LOI, hence a high carbon content, whereas the SCBA 3 and SCBA 4 values are low $(\leq 0.41)$. The high $\mathrm{LOI}$ agrees with former authors $[46,47]$ but comparable low values are also found in the literature $[17,26]$. The high LOI indicates temperatures in the low range and uncontrolled combustion.

The absence of high-temperature phases such as cristoballite and mullite, associated with temperatures above $800^{\circ} \mathrm{C}$, suggests production temperatures in the mediumto-low range agreeing with the high $\mathrm{LO}$.

The high LOI of ashes SCBA 1 and 2 is over the standard limits prescribed for pozzolans and SCMs such as FA and GGBS (Table 4). However, Chusilp et al. [24] and Ganesan et al. [28] state that a LOI up to $10 \%$ in sugar bagasse ashes does not significantly affect the compressive strength of the resultant concrete.

All the ashes comply with the sulphur and chloride limits established by EN and ASTM standards for other pozzolans and SCMs (Table 4). The sulphur and chloride contents are exceedingly low (Table 2), an outstanding quality for any material, as it lowers the risk of expansion by salt attack and delayed ettringite formation. The alkali content is also very low: the highest potassium content is $3.73 \%$ in SCBA2, and the sodium content marginal (highest in SCBA2 at $0.16 \%$ ) (Table 2). Alkalis can speed up the 


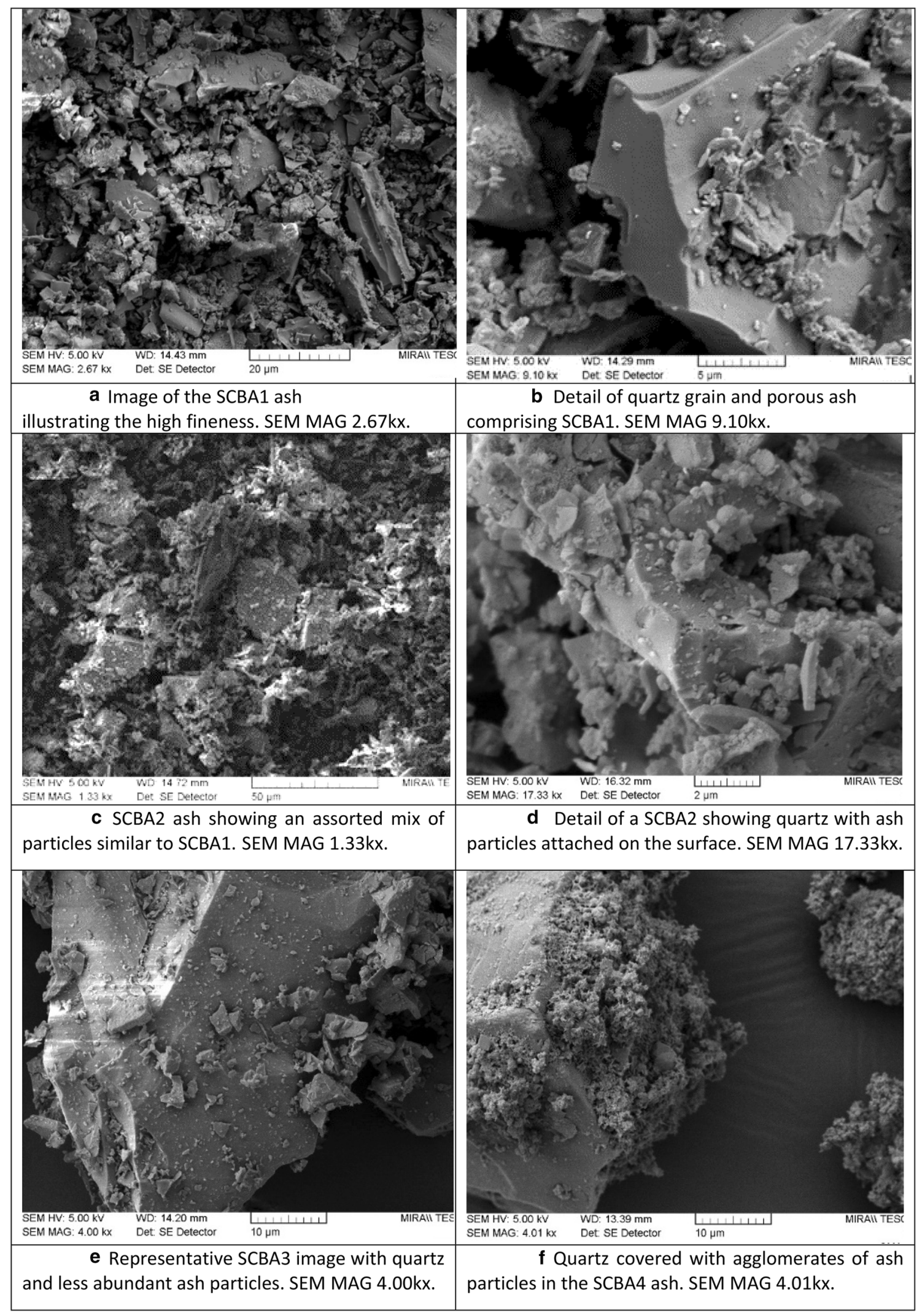

Fig. 2 SEM micrographs showing the microstructure of the SCBA ashes 
Table 2 Chemical composition of SCBAs as $\%$ oxide by mass

\begin{tabular}{|c|c|c|c|c|c|c|c|c|c|c|}
\hline & SCBAs & & & & Sales a & and Lim & a [37] & Cordeiro & Cordeiro & Ferreira et al. [46] \\
\hline & 1 & 2 & 3 & 4 & & & & & {$[11]$} & \\
\hline $\mathrm{SiO}_{2}$ & 39.00 & 59.10 & 96.80 & 93.40 & 62.7 & 93.5 & 96.2 & 70.5 & 80.8 & 66.80 \\
\hline $\mathrm{Al}_{2} \mathrm{O}_{3}$ & 13.65 & 4.19 & 0.74 & 1.69 & 4.5 & 1.2 & 0.2 & 10.1 & 5.1 & 7.70 \\
\hline $\mathrm{Fe}_{2} \mathrm{O}_{3}$ & 11.40 & 2.01 & 2.06 & 2.69 & 8.8 & 2.6 & 1.7 & 7.4 & 1.6 & 10.20 \\
\hline $\mathrm{CaO}$ & 3.19 & 2.42 & 0.25 & 0.36 & 0.9 & 0.4 & 0.1 & 4.2 & 3.1 & 0.94 \\
\hline $\mathrm{MgO}$ & 1.55 & 1.65 & 0.20 & 0.27 & 0.6 & 0.3 & $<0.1$ & - & - & 0.49 \\
\hline $\mathrm{K}_{2} \mathrm{O}$ & 1.95 & 3.73 & 0.49 & 0.71 & 1.8 & 0.8 & 0.3 & 1.8 & 6.3 & 1.03 \\
\hline $\mathrm{TiO}_{2}$ & 0.90 & 0.78 & 0.45 & 0.97 & 3.1 & 0.5 & 0.2 & 0.3 & 0.3 & - \\
\hline $\mathrm{P}_{2} \mathrm{O}_{5}$ & 1.16 & 1.25 & 0.15 & 0.16 & 0.7 & 0.2 & 0.1 & 1.1 & 0.8 & - \\
\hline $\mathrm{SO}_{3}$ & 0.21 & 0.81 & 0.02 & 0.03 & 0.2 & $<0.1$ & 0.1 & 2.3 & 1.5 & - \\
\hline $\mathrm{Na}_{2} \mathrm{O}$ & 0.00 & 0.16 & 0.00 & 0.00 & 0.1 & $<0.1$ & - & - & - & $<0.10$ \\
\hline $\mathrm{SrO}$ & 0.01 & 0.02 & $<0.01$ & $<0.01$ & - & - & - & - & - & - \\
\hline $\mathrm{BaO}$ & 0.02 & 0.05 & $<0.01$ & $<0.01$ & - & - & - & - & - & - \\
\hline $\mathrm{Cl}$ & 0.01 & 0.11 & 0.01 & 0.01 & - & - & - & - & - & - \\
\hline LOI & 24.10 & 23.60 & 0.41 & 0.31 & 16.28 & 0.34 & 1.04 & 2.2 & 0.4 & 11.47 \\
\hline
\end{tabular}

Table 3 Mineral composition of the sugar bagasse ashes

\begin{tabular}{lllllll}
\hline Material & Main minerals & Minor & Quartz & Hematite & Calcite & Corundum \\
\hline SCBA 1 & Quartz, hematite, calcite & Corundum & c.70\% & $6 \%$ & $6-7 \%$ & c.5\% \\
SCBA 2 & Quartz & Corundum, hematite & $>90 \%$ & c.5\% & - & c.5\% \\
SCBA 3 & Quartz & Hematite & $>90 \%$ & c.5\% & - & - \\
SCBA 4 & Quartz & Hematite & $>90 \%$ & c.5\% & - & - \\
\hline
\end{tabular}

$5 \%$ is the limit of detection of the technique. ICDD: Quartz (syn) 046-1045; hematite 24-72; corundum 46-1212; calcite 24-27

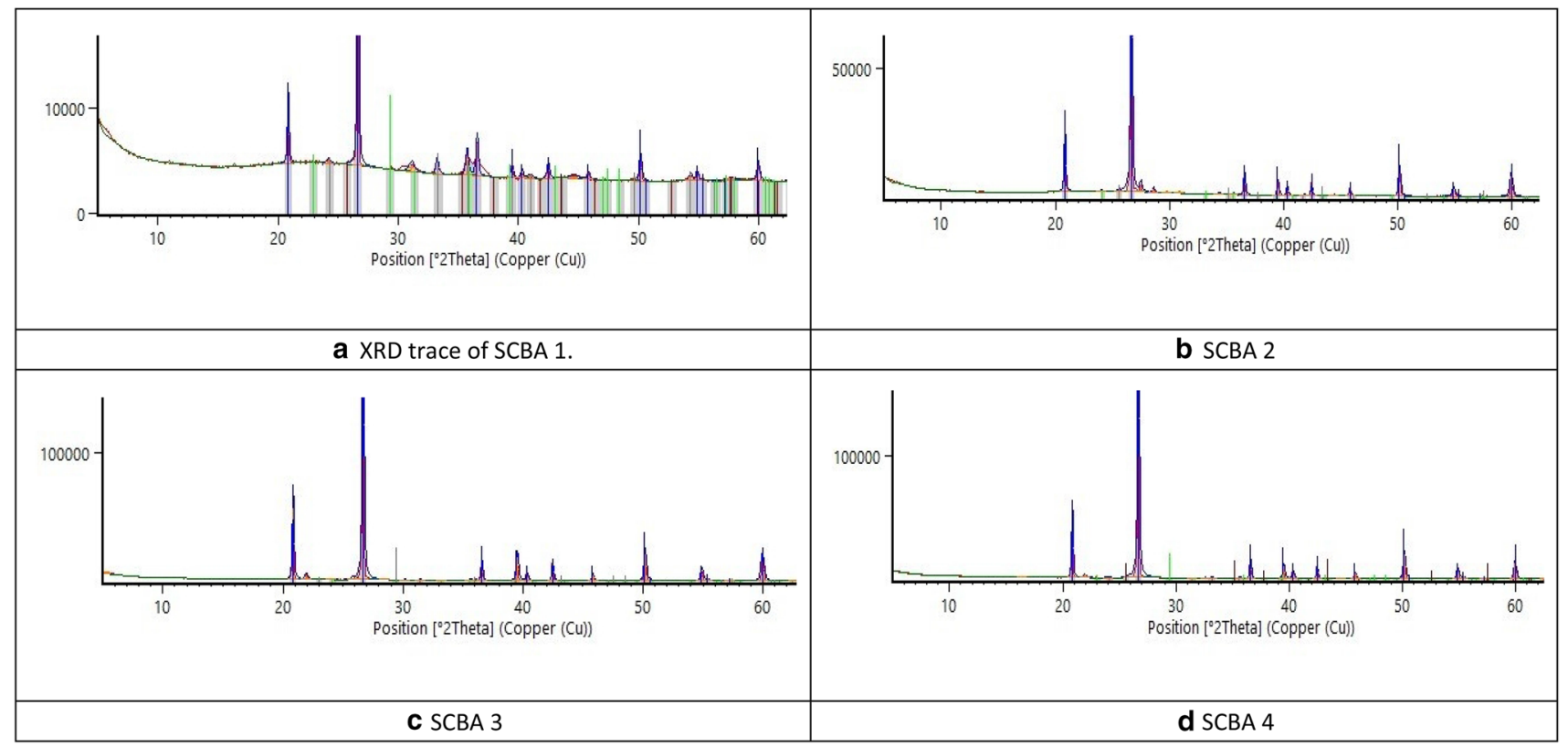

Fig. 3 Diffractograms of the ashes 
Table 4 Compliance of the sugar bagasse ashes with chemical requirements in standards for pozzolans and SCMs

\begin{tabular}{|c|c|c|c|c|c|c|}
\hline & $\% \mathrm{SO}_{3} / \mathrm{S}^{2-}$ & $\mathrm{MgO}(\%)$ & Total alkalis & $\mathrm{Cl}^{-}$ & LOI (\%) & $\Sigma(\mathrm{Si}, \mathrm{Al}, \mathrm{Fe})(\%)$ \\
\hline $\begin{array}{l}\text { EN 15167-1 -GGBS requirements for use in concrete, } \\
\text { mortar and grout [49] }\end{array}$ & $\leq 2-2.5$ & $\leq 18$ & - & $\leq 0.10$ & $\leq 3$ & - \\
\hline ASTM C618_FA requirements for use as a pozzolan [50] & $<5$ & - & - & - & $<10$ & $\begin{array}{l}\geq 70 \text { class } F \\
\geq 50 \text { class } C\end{array}$ \\
\hline EN450-1- FA requirements [40] & $\leq 3$ & $\leq 4$ & $\leq 5$ & $\leq 0.10$ & $<9$ & $\geq 70$ \\
\hline SCBA 1 & 0.21 & 1.55 & 1.95 & 0.01 & 24.10 & 64 \\
\hline SCBA 2 & 0.81 & 1.65 & 3.89 & 0.11 & 23.60 & 65 \\
\hline SCBA 3 & 0.02 & 0.20 & 0.49 & 0.01 & 0.41 & 99 \\
\hline SCBA 4 & 0.03 & 0.27 & 0.71 & 0.01 & 0.31 & 98 \\
\hline
\end{tabular}

Table 5 Amorphousness of the SCBAs

\begin{tabular}{llll}
\hline Material & Slope base & Slope hump & $\begin{array}{l}\text { Amor- } \\
\text { phous- } \\
\text { ness }\end{array}$ \\
\hline SCBA 1 & -37.052 & -63.128 & S-I \\
SCBA 2 & -36.039 & -61.599 & S-I \\
SCBA 3 & -28.228 & -40.974 & C \\
SCBA 4 & -0.002 & -0.002 & C \\
\hline
\end{tabular}

C, crystalline; S, slightly amorphous; I, intermediate

dissolution of amorphous silica initially favouring pozzolanic reaction; however, at later ages they adversely affect durability due to alkali-silica reaction forming expansive calcium-alkali-silicate-hydrate gels.

The amorphousness of the ashes was loosely categorised based on the slope of the diffractogram's base line and the background area determined by the lifting of the baseline between 15 and $35(2 \Theta)$ which indicates the presence of amorphous materials. This broad hump cannot be accurately measured; however, the vitreous character of a pozzolanic material is indicated by the size of the hump [48]. According to these results (Table 5), SCBA 1 is the most amorphous (slight to intermediate amorphousness).

\subsection{Reactivity by electrical conductivity}

It could be argued that there are errors in the conductivity measurements due to two issues: the ashes being soluble in water, and the presence of soluble salts within the ashes. If these were true, these additional cations and anions would affect conductivity inducing errors in the measurement. However, this is not the case in the ashes investigated because the conductivity of ash-water solutions was measured and found negligible $(<1 \mathrm{mS})$, and the anion and alkali content of the ashes is extremely low (Table 2 ). In addition, a further error could have been introduced by allowing the process of carbonation fixing the $\mathrm{Ca}(\mathrm{OH})_{2}$
Table 6 Summary of the conductivity variation of the lime-ash solutions

\begin{tabular}{llc}
\hline Material & $\begin{array}{l}\text { Total conductivity loss } \\
(\%)\end{array}$ & $\begin{array}{l}\text { Conductivity drop } \\
\text { the first 24 h (\%) }\end{array}$ \\
\hline SCBA 1 & 18.37 & 10.61 \\
SCBA 2 & 21.02 & 11.12 \\
SCBA 3 & 13.47 & 9.90 \\
SCBA 4 & 17.65 & 10.20 \\
\hline
\end{tabular}

in suspension, rather than the ashes and their pozzolanic reaction. However, the suspensions were kept tightly closed during the test to avoid $\mathrm{CO}_{2}$ inducing carbonation.

The carbon content can impede lime combination by the ash, hence interfering with the results of the conductivity test. However, the results show that the ashes with the highest carbon content (SCBA 1 and 2) combine significant lime showing activity.

In addition, from the differing particle size distributions, it was expected that the finer ashes would combine more lime earlier, leading to more substantial conductivity changes. This is the case, as the finest ashes (SCABA1 and 2) show the greatest conductivity losses.

This method is adopted from de Luxan et al. who tested natural pozzolanic materials including opaline rocks and diatomite earths and volcanic tuffs. These materials are significantly more reactive than our sugar waste ashes. Therefore, we have extended the testing time to provide detail on the early and late reactivity (up to 7 days), and we calculate the conductivity drop in the first $24 \mathrm{~h}$. The total conductivity loss and the loss in the first $24 \mathrm{~h}$ are included in Table 6.

Conductivity loss over time is clear in all the lime/ ash solutions (Fig. 4), indicating that all the ashes combine lime, hence showing reactivity. SCBA 2 showed a superior conductivity loss suggesting the greatest activity, closely followed by SCBA 1 and 4 . The conductivity results agrees with the expected reactivity based on the 
Fig. 4 Pozzolanic activity evidenced by the change in the electrical conductivity of ash-lime suspensions over a period of 7 days

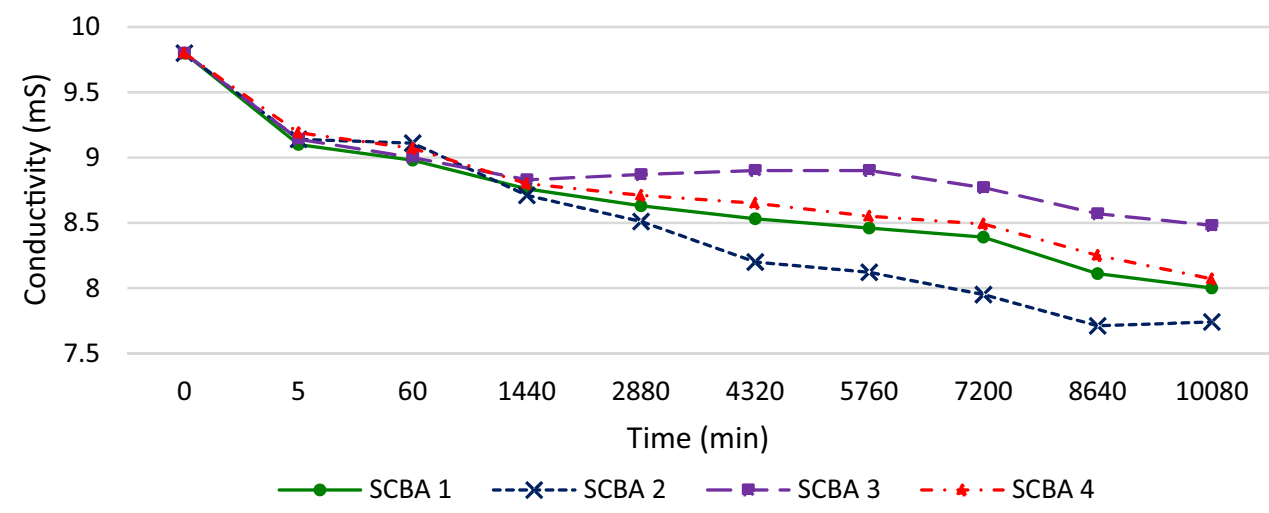

specific surface area, rating the SCBA 2 ash as the most reactive ash followed by SCBA 1, with the SCBA 4 and SCBA 3 ashes being the least reactive (Table 6).

During the first $24 \mathrm{~h}$ (up to 1440 min-Fig. 4), the curves show steep slopes whereby all the ashes combine the most lime and the conductivity of the solutions significantly lowers. After $24 \mathrm{~h}$, the lesser steep curves indicate a drop in the reaction rate. SCBA 3 shows a dormant period where the curve is flat tending to inverted. On the contrary, SCBA2 still combines significant lime producing the steepest curve which evidences sustained reactivity. SCBA 1 and 4 also show a sustained, although small, activity.

The conductivity values in Table 6 are in agreement, with previous authors [41] which showed conductivity reduction, in the first $24 \mathrm{~h}$, ranging between 10 and $30 \%$ (for 9 pozzolanic materials) and are higher than those found by Tashima et al. [51] for rice husk ash (RHA). Cordeiro and Kurtis [11] claim that coarse ashes ( $\mathrm{D} 50=30 \mu \mathrm{m}$ ) behave as inert mineral additions, SCBA 3 and 4 are close to this value; however, they combine $9-10 \%$ lime in the first $24 \mathrm{~h}$.

\subsection{Reactivity by strength development}

The SCBA 2 specimens achieved the highest compressive strength, up to $3.62 \mathrm{~N} / \mathrm{mm}^{2}$ (Table 7), followed by the SCBA 1 specimens at $1.95 \mathrm{~N} / \mathrm{mm}^{2}$. The SCBA 4 and SCBA 3 specimens reached similar strengths at 1.65 and $1.23 \mathrm{~N} / \mathrm{mm}^{2}$, respectively. The particle size distribution of the SCBA 1 and 2 ashes, which favours a filler effect, might have contributed to the higher strength results.

The flexural strengths are similar, but the results do not show any specific trend. However, the SCBA 1 and 4 ashes surpassed the flexural strength of the reference (hydrated lime) specimen. According to the strength results, SCBA2 is the most reactive ash followed by SCBA 1 . Only the SCBA2 ash improved the compressive strength of the hydratedlime mix. The strength drop is due to the lower hydratedlime content producing less-carbonated lime binder and resembles the dilution effect reported in cement technology when cement is increasingly replaced with mineral admixtures. The mechanical indices are lower than others previously measured for highly reactive materials such as GGBS (29.5) and microsilica (12.5), but comparable or slightly under those of ceramic dusts (1-3) and some fly ashes (3.4) measured by Walker and Pavia [41]. They also
Table 7 Mechanical properties and mechanical indices for SCBA 1 and SCBA 2 specimens $(1: 1: 3: 2)$ and SCBA 3 and SCBA 4 specimens $(1: 1: 3: 1.5)$ (lime:ash:sand:water)

\begin{tabular}{|c|c|c|c|c|c|c|}
\hline \multirow[t]{2}{*}{ Material } & \multirow[t]{2}{*}{$\begin{array}{l}\text { Compressive } \\
\text { strength ( } \mathrm{MPa})\end{array}$} & \multirow{2}{*}{$\begin{array}{l}\text { Flexural } \\
\text { strength } \\
(\mathrm{MPa})\end{array}$} & \multicolumn{2}{|c|}{ Mechanical index } & \multicolumn{2}{|c|}{$\begin{array}{l}\text { Strength variation (\%) with } \\
\text { respect to the reference }\end{array}$} \\
\hline & & & $\begin{array}{l}\text { Com- } \\
\text { pressive } \\
\text { strength }\end{array}$ & $\begin{array}{l}\text { Flexural } \\
\text { strength }\end{array}$ & $\begin{array}{l}\text { Com- } \\
\text { pressive } \\
\text { strength }\end{array}$ & Flexural strength \\
\hline $\begin{array}{l}\text { Ref.- } \\
\text { hydrated } \\
\text { lime only }\end{array}$ & $2.45(1.12)$ & $0.39(2.47)$ & - & - & - & - \\
\hline SCBA 1 & $1.95(4.70)$ & $0.41(1.80)$ & 0.8 & 1.0 & -20.66 & 8.75 \\
\hline SCBA 2 & $3.62(2.15)$ & $0.36(4.30)$ & 1.5 & 0.9 & 47.46 & -8.06 \\
\hline SCBA 3 & $1.35(3.16)$ & $0.28(2.66)$ & 0.6 & 0.7 & -44.83 & -28.05 \\
\hline SCBA 4 & 1.65 (1.09) & $0.46(5.22)$ & 0.7 & 1.2 & -32.95 & 16.83 \\
\hline
\end{tabular}

The italics are the coefficient of variation (\%) in brackets 
agree with Moropoulou et al. [52] who attained flexural strengths ranging from 0.34 to $0.38 \mathrm{MPa}$ using earth of milos and brick powder.

\subsection{Microstructure and kinetics of reaction of sugar bagasse ash/hydrated-lime pastes}

The pozzolanic reaction mechanism is slow and has been well documented by previous authors [12]. According to this reaction, when water is added to the ash and lime, the lime $-\mathrm{Ca}(\mathrm{OH})_{2}$-quickly dissociates into $\mathrm{Ca}^{2+}$ and $\mathrm{OH}^{-}$according to the equation below, producing a solution with a high $\mathrm{pH}$.

$$
\mathrm{Ca}(\mathrm{OH})_{2} \rightarrow \mathrm{Ca}^{2+}+2 \mathrm{OH}^{-}
$$

In this alkaline solution, the $\mathrm{Ca}^{2+}$ as well as other soluble phases in the pozzolan (alkalis, sulphates and chlorides) dissolve contributing with their ions to the solution. The alkaline medium also causes the pozzolan's silicates to break down (mainly the amorphous phases) and dissolve into the solution according to Shi and Day [25]:

$$
\begin{aligned}
& \equiv \mathrm{Si}-\mathrm{O}-\mathrm{Si} \equiv+3 \mathrm{OH}^{-} \rightarrow\left[\mathrm{SiO}(\mathrm{OH})_{3}\right]^{-} \\
& \equiv \mathrm{Si}-\mathrm{O}-\mathrm{Al} \equiv+3 \mathrm{OH}^{-} \rightarrow\left[\mathrm{SiO}(\mathrm{OH})_{3}\right]^{-}+\left[\mathrm{Al}(\mathrm{OH})_{4}\right]^{-}
\end{aligned}
$$

$\mathrm{Ca}^{2+}$ ions combine with these dissolved silicate and aluminate anions to form $\mathrm{C}-\mathrm{S}-\mathrm{H}$ and calcium aluminate hydrates. The nature of these hydrates largely depends on the concentration of the ions in solution. Therefore, it was expected that the reaction between the hydrous silica in the ashes and the lime would produce $\mathrm{C}-\mathrm{S}-\mathrm{H}$. The aluminium content of the ashes is very low except for SCBA 1 (Table 2); hence, aluminate hydrates were hardly expected. Furthermore, the mineral analysis evidenced that most of the aluminium in the ashes is present as crystalline corundum $\left(\mathrm{Al}_{2} \mathrm{O}_{3}\right)$ which is hardly soluble in any solvent, even in the alkaline solution produced by the hydrolysis of lime.

Despite the crystalline composition of the ashes, including silica as quartz and little reactive aluminium, $\mathrm{C}-\mathrm{S}-\mathrm{H}$ and $\mathrm{C}-\mathrm{A}-\mathrm{S}-\mathrm{H}$ were evidenced early (7 days) in the SCBA 1 and SCBA 2 pastes, which also displayed the highest flexural and compressive strengths. Hydrates, showing needle-like morphologies and significant crystallinity were evidenced in the SCBA 1 pastes at 7 days (Fig. 5). These hydrates are similar to products found in lime-RHA

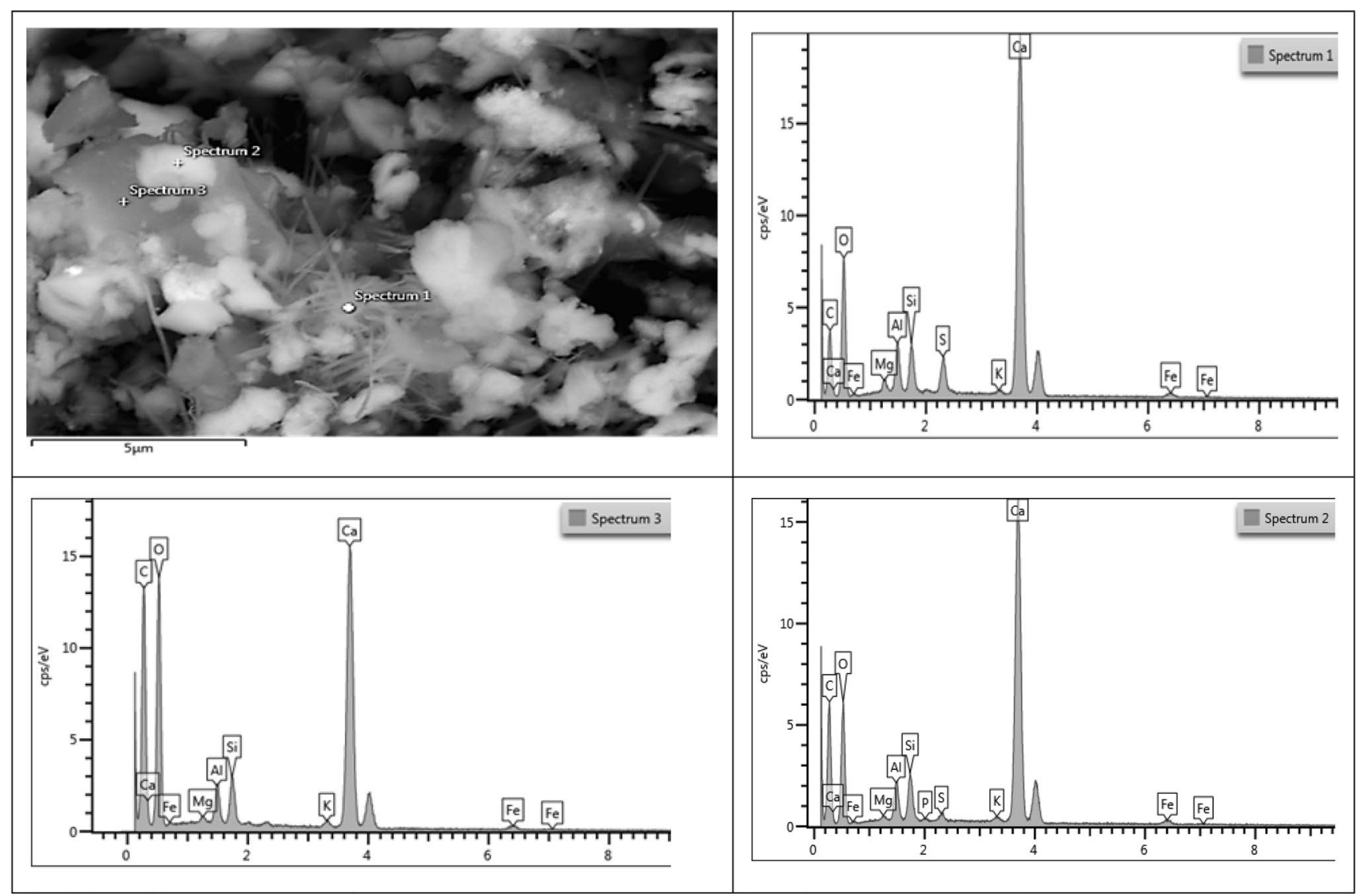

Fig. 5 Lime-SCBA 1 paste at 7 days showing needle-shaped hydrates (EDS spectrum 1), carbonated lime (EDS spectrum 2) and remains of organic matter (EDS spectrum 3) 
samples [44]. Alike hydrates have been reported in SCBA pastes by previous authors $[20,21,53]$. At 7 days, the pastes showed the open porous structure typical of lime mortars, with hexagonal portlandite $(\mathrm{CH})$ plates and abundant, irregular carbonated particles $\left(\mathrm{Ca} \mathrm{CO}_{3}\right)$ (Figs. 5, 6). At 28 days, (Fig. 7) denser microstructures were evident comprising abundant carbonated lime and scarce hydrates. At later ages, $\mathrm{CH}$ seldom occurs, indicating that the pozzolanic reaction is practically completed, as the consumption of $\mathrm{CH}$ over time confirms pozzolanic activity. The qualitative nature of the SEM/EDS analyses did not allow to rate the ashes based on the microscopic study.

As the pozzolanic reaction has a varying stoichiometry, the calcium/silicon (C/S) ratios of the $\mathrm{C}-\mathrm{S}-\mathrm{H}$ hydrates vary, and $\mathrm{C} / \mathrm{S}$ ratios ranging from 0.6 to 2.0 have been found by previous authors [54, 55]. Pereira et al. [55] identified amorphous matrices in sugarcane straw ash and cement mixes with molar ratios $\mathrm{C} / \mathrm{S}=0.60, \mathrm{Al} / \mathrm{Si}=0.63, \mathrm{Na} / \mathrm{Si}=1.34$, and $\mathrm{K} / \mathrm{Si}=0.05$. These ratios are similar to those found upon hydration of the lime-ash pastes in this study (Table 8).

\section{Discussion}

As it can be seen from Table 7, the finest and most amorphous ashes (SCBA 1 and 2), with the greatest surface area (mainly SCBA2), are the most reactive, and, despite their high carbon content, they combined the most lime and reached the greatest strengths. The ash with the greatest surface area combines the most lime, agreeing with former
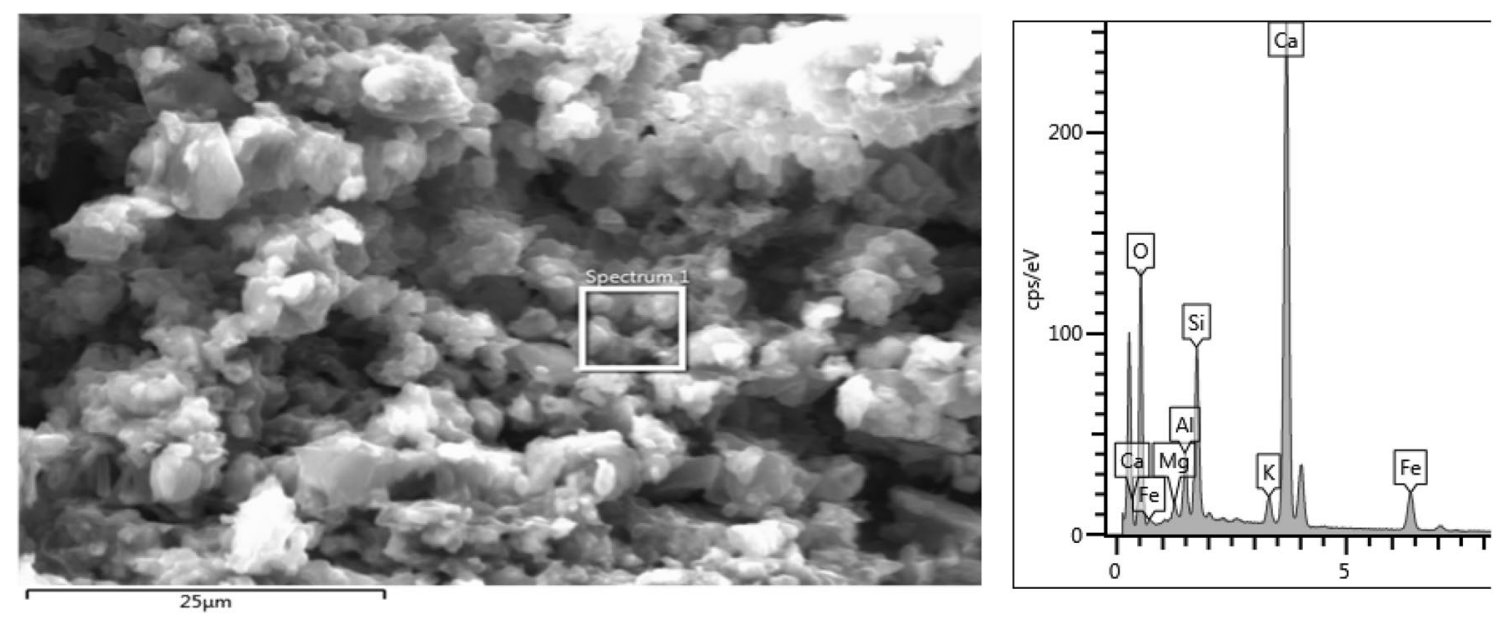

Fig. 6 Lime-SCBA 2 paste showing a porous structure with hexagonal portlandite, carbonated lime and C-A-S-H phases identified by EDS at 7 days
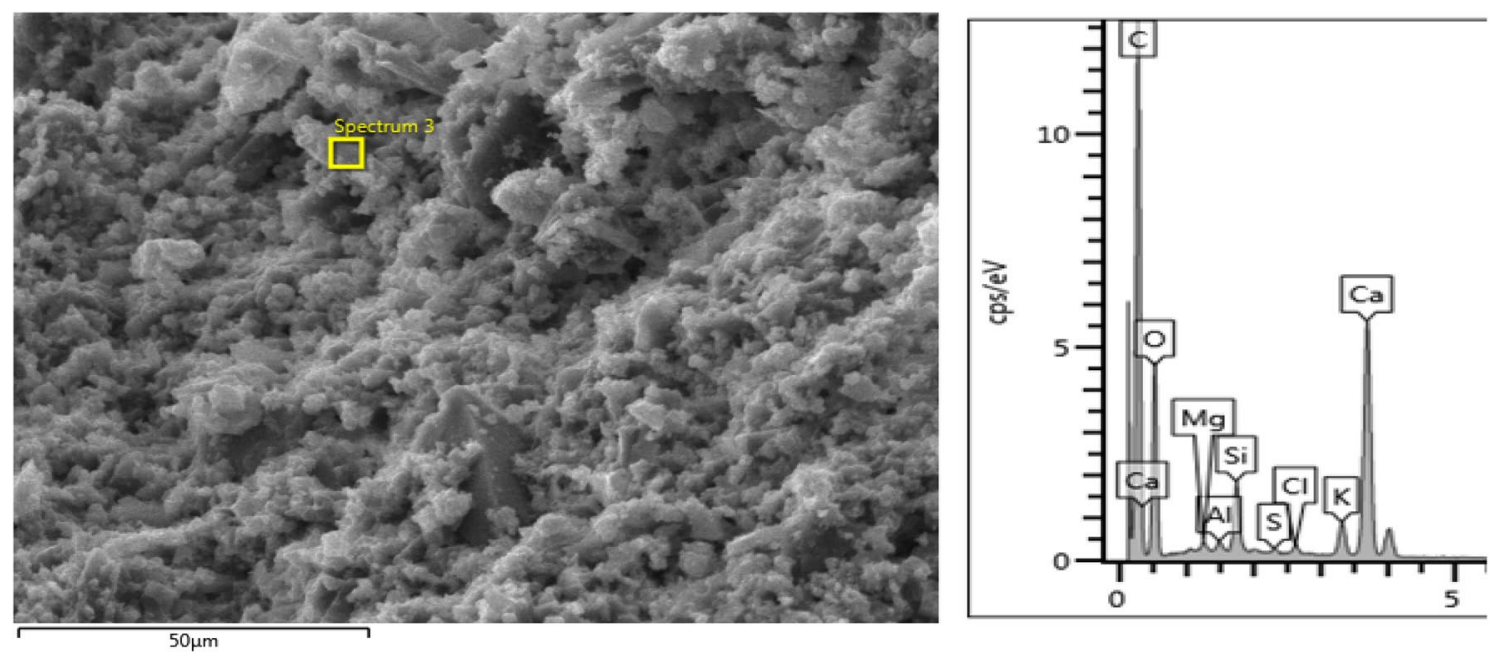

Fig. 7 A representative image of the denser lime-SCBA 2 pastes, at 28 days, showing strong carbonation 
Table 8 Chemical composition of mineral phases in the lime paste determined by SEM/EDS

\begin{tabular}{|c|c|c|c|c|c|c|c|c|c|c|}
\hline Material & $\mathrm{Ca}$ & $\mathrm{Si}$ & $\mathrm{C} / \mathrm{S}$ & $\mathrm{Al}$ & $\mathrm{Mg}$ & K & $\mathrm{Fe}$ & $S$ & $\mathrm{Cl}$ & Ref. Figure \\
\hline SCBA 1-7 d (1) & 14.7 & 11.6 & 1.3 & 1.1 & 0.3 & 0.1 & 0.3 & 1 & - & Figure 5 \\
\hline SCBA 1-7 d (2) & 12.1 & 9.1 & 1.3 & 0.8 & 0.1 & 0.1 & 0.2 & 0.2 & - & Figure 5 \\
\hline SCBA 1-7 d (3) & 11.5 & 20 & 0.6 & 0.9 & 0.1 & 0.2 & 0.3 & - & - & Figure 5 \\
\hline SCBA 2-7 d & 164.2 & 91.2 & 1.8 & 16 & 3.9 & 8.3 & 29.4 & - & - & Figure 6 \\
\hline SCBA $2-28 d$ & 2.5 & 4.2 & 0.6 & 0.1 & 0.1 & 0.3 & - & - & 0.06 & Figure 7 \\
\hline
\end{tabular}

Relative proportions and $\mathrm{C} / \mathrm{S}$ ratio

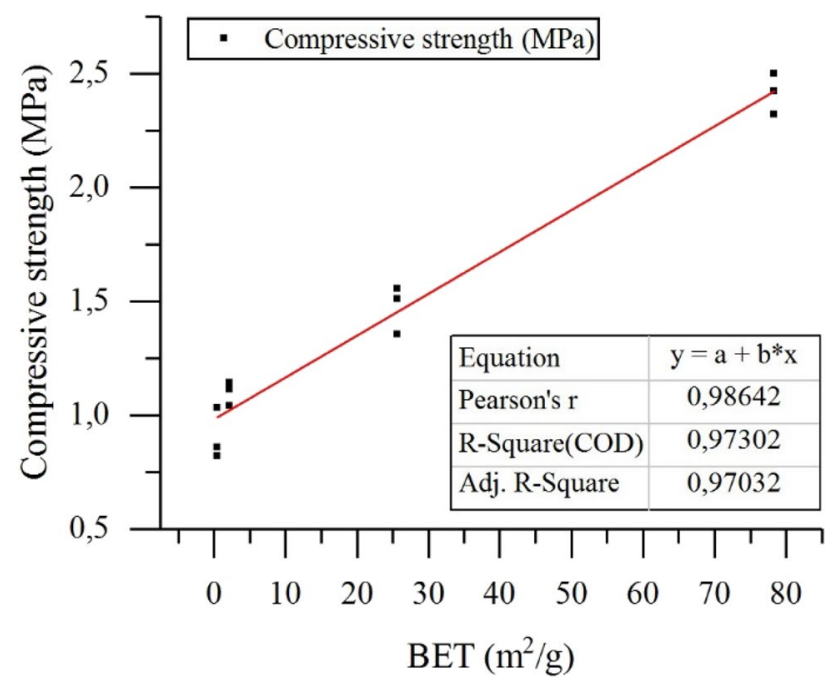

Fig. 8 Relationship between the specific surface area and the compressive strength of the SCBAs

authors who state that the pozzolanic reaction is initially governed by the specific surface area [12].

A positive correlation (Pearson's $r=0.986$ ) exists between the specific surface area of the ashes and their compressive strength (Fig. 8), agreeing with Cordeiro and Kurtis [11]. A positive correlation (Pearson's $r=0.874$ ) also exists between the chemical reactivity determined with the conductivity test and the compressive strength (Fig. 9), agreeing with Walker and Pavia [13].

The results evidence that reactivity increases with rising amorphousness, fineness and surface area, and that the carbon content does not eliminate reactivity: the ashes with the greatest carbon content (SCBA 1 and 2) show more significant strength development and early lime combination, whereas SCBA 3 and SCBA 4, with lower carbon $(\mathrm{LOI} \leq 0.41)$, present low reactivity. This agrees with Chusilp et al. [24] who claim that high carbon content in ground bagasse ash does not adversely affect the properties of a mortar.

The lower reactivity of the SCBA ashes 3 and 4 is partly due to strong contamination with soil sand (quartz).

It is widely acknowledged that not only the chemical evolution of the pozzolanic reaction but also the physical

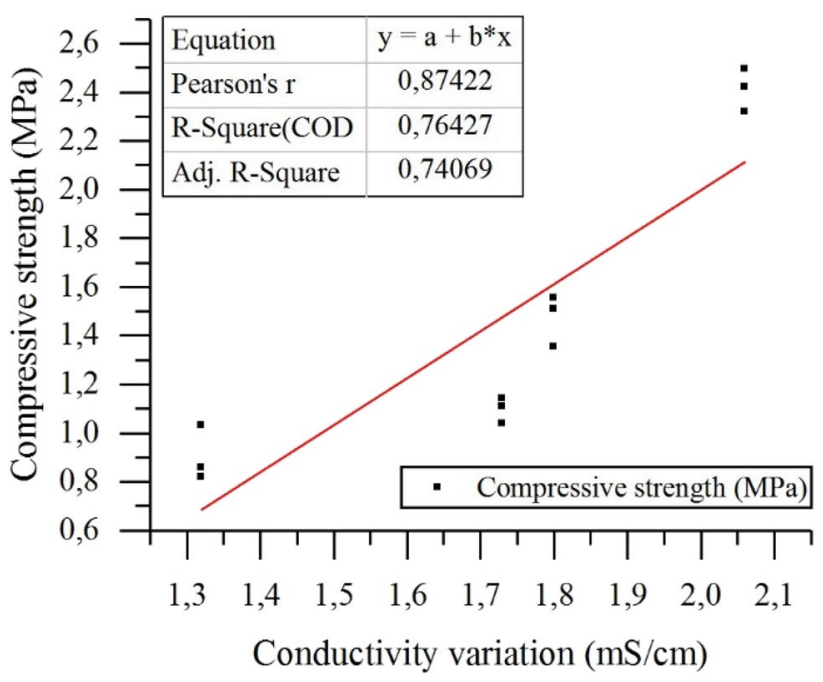

Fig. 9 Relationship between the conductivity variation and the compressive strength of the SCBAs

filler effect of the pozzolans contribute to the strength of pozzolan composites. However, in the ashes studied, the pozzolanic reaction seems to override the physical effect, as the strength does not seem to change significantly with decreasing particle size.

It seems to form the results that the alumina, iron and alkali content in the ashes are too low to affect pozzolanic activity, as SCBA1 has the highest contents, and yet, SCBA 2 combines more lime in the short term and reaches greater strength. However, this trend is likely to change if the ashes were to contain higher amounts of these elements. Also, the iron and aluminium are present as hematite and corundum which are highly insoluble and unlikely to participate in the pozzolan-lime reactions (Tables 3 and 9).

\section{Conclusion}

The sugar bagasse ashes investigated show pozzolanic activity. C-S-H was evident at 7 days, and the ashes combined lime and produced strengths similar or superior 
Table 9 Summary of results

\begin{tabular}{|c|c|c|c|c|c|c|c|c|c|c|c|c|c|c|}
\hline \multirow[t]{2}{*}{ Ash } & \multirow[t]{2}{*}{ SSA } & \multicolumn{2}{|c|}{ Fineness \% } & \multirow{2}{*}{$\begin{array}{l}\text { Amor- } \\
\text { phous- } \\
\text { ness }\end{array}$} & \multirow[t]{2}{*}{ LOI } & \multicolumn{5}{|c|}{ Chemical composition } & \multicolumn{2}{|c|}{$\begin{array}{l}\text { Conductivity } \\
\text { drop }\end{array}$} & \multicolumn{2}{|l|}{ Strength } \\
\hline & & $>45 \mu \mathrm{m}$ & $>75 \mu \mathrm{m}$ & & & $\mathrm{SiO}_{2}$ & $\mathrm{Al}_{2} \mathrm{O}_{3}$ & $\mathrm{Fe}_{2} \mathrm{O}_{3}$ & $\mathrm{CaO}$ & $\mathrm{K}_{2} \mathrm{O}$ & $24 \mathrm{~h}$ & Total & $\mathrm{CsMPa}$ & $\mathrm{FsMPa}$ \\
\hline SCBA 1 & 25.63 & 6.19 & 3.35 & S-I & 24.10 & 39.00 & 13.65 & 11.40 & 3.19 & 1.95 & 10.61 & 18.37 & 1.95 & 0.41 \\
\hline SCBA 2 & 78.33 & 6.19 & 1.18 & S-I & 23.60 & 59.10 & 4.19 & 2.01 & 2.42 & 3.73 & 11.12 & 21.02 & 3.62 & 0.36 \\
\hline SCBA 3 & 0.51 & 44.72 & 32.96 & $\mathrm{C}$ & 0.41 & 96.80 & 0.74 & 2.06 & 0.25 & 0.49 & 9.90 & 13.47 & 1.35 & 0.28 \\
\hline SCBA 4 & 2.19 & 42.50 & 30.41 & C & 0.31 & 93.40 & 1.69 & 2.69 & 0.36 & 0.71 & 10.20 & 17.65 & 1.65 & 0.46 \\
\hline
\end{tabular}

to the control mix at 28 days. Ever the coarse ashes with lower specific surface areas combine lime and produce strengths comparable to the control specimen.

Despite the low amorphousness and high carbon contents of some of the ashes, reactivity was evidenced by means of physical and chemical tests, and the results of the mechanical index and conductivity tests are comparable to those by previous authors. The ashes show activity despite the presence of significant crystalline phases such as quartz, corundum and the iron oxide hematite, that are considered non-reactive. In addition, the ashes with the greatest carbon content are the most reactive and their composites reached the highest strength. Fineness triggers the physical packing effect of the pozzolans that increases the strength; however, in the ashes studied, the reactivity seems to override the physical effect, as the strength does not seem to change significantly with decreasing particle size.

A positive correlation exists between the compressive strength and the specific surface area; and between the compressive strength and the chemical activity agreeing with previous authors. It seems from the results that the alumina, iron and alkali content in the ashes do not affect pozzolanic activity, as SCBA 1 has the highest contents, and yet, SCBA 2 combines more lime in the short term and reaches a greater 28-day strength. Some of these elements are present as hematite and corundum which are highly insoluble and unlikely to participate in the pozzolan-lime reactions.

The anions and alkalis capable of forming detrimental salts and causing expansion are extremely low or nonexistent in the ashes, well under the standard requirements for fly ash and GGBS.

The reactivity, together with the lack of dangerous and toxic components, place these ashes in a favourable standpoint to be used as binder replacement in construction.

Acknowledgements The authors wish to thank the Brazilian National Council for Scientific and Technological Development (CNPq)-Ministry of Science, Technology, Innovations and Communications-for financing this investigation (Process Number: 201649/2015-2). The authors thank Dr Kevin Ryan, Chief Technician; Michael Grimes of the Materials Laboratory; and Eoin Dunne of the Geothecnical
Laboratory in the Department of Civil Engineering for their help with physical testing; Dr. Aran Rafferty of CRANN for his assistance with the BET/SEM analysis.

\section{Compliance with ethical standards}

Conflict of interest The authors declare that they have no conflict of interest.

\section{References}

1. Chen JRQ, Soboyejo A (2015) Survey of the current status of sustainable concrete production in the U.S. Resources. Conserv Recycl 105(Part A):148-159

2. Shafigh $P$, Mahmud HB, Jumaat MZ, Zargar M (2014) Agricultural wastes as aggregate in concrete mixtures-a review. Constr Build Mater 53:110-117

3. EN 197-1:2011 Cement. Composition, specifications and conformity criteria for common cements

4. Cembureau TECA Report (2016) Key facts: Cement industry contibutes to waste management. https://cembureau.eu/library/

5. Cembureau TECA Report (2014) The Role of cement in the 2050 low-carbon economy. https://cembureau.eu/library/

6. Worrell E, Price L, Martin N, Hendriks C, Meida LO (2001) Carbon dioxide emissions from the global cement industry. Annu Rev Energy Environ 26(1):303-329

7. CONAB CNdA (2018) Acompanhamento da Safra Brasileira de Cana de Açúcar: Safra 2017/2018. 2018(Fourth survey)

8. Cordeiro GC, Tavares LM, Toledo Filho RD (2016) Improved pozzolanic activity of sugar cane bagasse ash by selective grinding and classification. Cem Concr Res 2016(89):269-275

9. Sales A, Lima SA (2010) Use of Brazilian sugarcane bagasse ash in concrete as sand replacement. Waste Manag 30(6):1114-1122

10. Souza AE, Teixeira SR, Santos GTA, Costa FB, Longo E (2011) Reuse of sugarcane bagasse ash (SCBA) to produce ceramic materials. J Environ Manag 92:2774-2780

11. Cordeiro GC, Kurtis KE (2017) Effect of mechanical processing on sugar cane bagasse ash pozzolanicity. Cem Concr Res 97:41-49

12. Massazza F (1998) Pozzolana and pozzolanic cements. In: Hewlett PC (ed) Lea's chemistry of cement and concrete, 4th edn. Elsevier, London, pp 471-602

13. Walker R, Pavía S (2010) Behaviour and properties of Lime-Pozzolan pastes. In: Jäger W, Haseltine B, Fried A (eds) 8th international masonry conference, Dresden, July 2010, pp 353-362

14. Massazza F (2002) Properties and applications of natural pozzolans. In: Bensted J, Barnes JP (eds) Structure and performance of cements. Spon Press, London 
15. Pavía S (2008) A petrographic study of the technology of hydraulic mortars at masonry bridges, harbours and mill ponds. In: Cannon E, West R, Fanning P (ed) Concrete research and bridge infrastructure symposium, Galway, Galileo Editions, pp 253-264

16. Pavía S (2008) A petrographic study of mortar hydraulicity. In: $\mathrm{HMC08,} \mathrm{mortars:} \mathrm{characterization,} \mathrm{diagnosis,} \mathrm{conservation,}$ repair and compatibility. LNEC, Laboratorio General Engenharia Civil, Lisbon

17. Payá J, Monzó J, Borrachero MV, Díaz-Pinzón L, Ordóñez LM (2002) Sugar-cane bagasse ash (SCBA): studies on its properties for reusing in concrete production. J Chem Technol Biotechnol 77(3):321-325

18. Torres J, Mejía R, Escandón CE, González LO (2014) Characterization of sugar cane bagasse ash as supplementary material for Portland cement. Ingeniería e Investigación 34(1):5-10

19. de Soares M, Garcia DCS, Figueiredo RB, Aguilar MTP, Cetlin PR (2016) Comparing the pozzolanic behavior of sugar cane bagasse ash to amorphous and crystalline SiO2. Cem Concr Compos 71:20-25

20. Martirena-Hernández JF, Middendorf B, Gehrke M, Budelmann $H$ (1998) Use of wastes of the sugar industry as pozzolana in lime-pozzolana binders: study of the reaction. Cem Concr Res 28(11):1525-1536

21. Frías M, Villar-Cociña E, Valencia-Morales E (2007) Characterisation of sugar cane Straw waste as pozzolanic material for construction: Calcining temperature and kinetic parameters. Waste Manag 27(4):533-538

22. Cordeiro GC, Toledo Filho RD, Fairbairn EMR (2009) Effect of calcination temperature on the pozzolanic activity of sugar cane bagasse ash. Constr Build Mater 23:3301-3303

23. Bahurudeen A, Santhanam M (2015) Influence of different processing methods on the pozzolanic performance of sugarcane bagasse ash. Cem Concr Compos 56:32-45. https://doi. org/10.1016/j.cemconcomp.2014.11.002

24. Chusilp N, Jaturapitakkul C, Kiattikomol K (2009) Effects of LOI of ground bagasse ash on the compressive strength and sulfate resistance of mortars. Constr Build Mater 23(12):3523-3531

25. Shi C, Day RL (2000) Pozzolanic reaction in the presence of chemical activators: Part I. reaction kinetics. Cem Concr Res 30(1):51-58. https://doi.org/10.1016/S0008-8846(99)00205-7

26. Cordeiro GC, Toledo Filho RD, Tavares LM, Fairbairn EMR (2008) Pozzolanic activity and filler effect of sugar cane bagasse ash in Portland cement and lime mortars. Cem Concr Compos 30:410-418

27. Arenas-Piedrahita JC, Montes-García P, Mendoza-Rangel JM, López-Calvo HZ, Valdez-Tamez PL, Martínez-Reyes J (2016) Mechanical and durability properties of mortars prepared with untreated sugarcane bagasse ash and untreated fly ash. Constr Build Mater 105:69-81

28. Ganesan K, Rajagopal K, Thangavel K (2007) Evaluation of bagasse ash as supplementary cementitious material. Cem Concr Compos 29:515-524

29. Oliveira de Paula M, Ferreira Tinôco IF, De Souza Rodrigues C, Osorio Saraz JA (2010) Sugarcane Bagasse ash as a partial-Portland-cement-replacement material. Revista Dyna 77:47-54

30. Chusilp N, Jaturapitakkul C, Kiattikomol K (2009) a Utilization of bagasse ash as a pozzolanic material in concrete. Constr Build Mater 23(11):3352-3358

31. Rerkpiboon A, Tangchirapat W, Jaturapitakkul C (2015) Strength, chloride resistance, and expansion of concretes containing ground bagasse ash. Constr Build Mater 101(1):983-989

32. Berenguer RA, Capraro APB, Farias de Medeiros MH, Carneiro AMP, De Oliveira RA (2020) Sugar cane bagasse ash as a partial substitute of Portland cement: effect on mechanical properties and emission of carbon dioxide. J Environ Chem Eng. https:// doi.org/10.1016/j.jece.2020.103655

33. Wei-Ting L, Hsin-Lung H, Cheng A, Huang R, Huang CC (2012) Using sugarcane bagasse ash as partial cement replacement in cement-based composites. Adv Sci Lett 13(1):762-767

34. Janjaturaphan S, Wansom S (2010) Pozzolanic activity of industrial sugar cane bagasse ash. Suranaree J Sci Technol 17(4):349-357

35. Maldonado-Bandala V, Jimenez-Quero FJ, Olguin-Coca LG, Lizarraga MA, Baltazar-Zamora F Almeraya-Calderon (2011) Electrochemical characterization of modified concretes with sugar cane bagasse ash. Int J Electrochem Sci 6:4915-4926

36. Arif E, Clark MW, Lake N (2016) Sugar cane bagasse ash from a high efficiency co-generation boiler: applications in cement and mortar production. Constr Build Mater 128:287-297

37. Sales A, Lima SA (2010) Use of Brazilian Sugarcane Bagasse Ash in Concrete as Sand Replacement. Waste Manag 30:1114-1122

38. EN 459-1:2010. Specifications, definitions and conforming criteria for building limes. European Comittee for Normalistion. CEN

39. De Luxan MP, Madruga F, Saavedra J (1989) Rapid evaluation of pozzolanic activity of natural products by conductivity measurement. Cem Concr Res 19:63-68

40. EN 450-1:2012. Fly ash for concrete. Definition, specifications and conformity criteria. European Comittee for Normalisation. CEN

41. Walker R, Pavia S (2011) Physical properties and reactivity of pozzolans, and their influence on the properties of lime-pozzolan pastes. Mater Struct 44(6):1139-1150

42. EN 196-1:2005 Methods of Testing Cement. European Comittee for Normalisation. CEN

43. Mehta PK (1986) Concrete. Structure, properties and materials. Prentice-Hall, Englewood Cliffs

44. Pavía S., Walker R., Veale P., Wood A. (2014) Impact of the properties and reactivity of rice husk ash (RHA) on lime mortar properties, ASCE American Society of Civil Engineers Journal of Materials in Civil Engineering, Vol.26 Issue 9 http://dx.doi.org/10.1061/ (ASCE)MT.1943-5533.0000967

45. Joshi RC (1970) Pozzolanic reactions in synthetic fly ashes. Ph.D. Dissertation, lowa University USA

46. Ferreira RTL, Nunes F, Bezerra ACdS, Figueiredo RB, Cetlin PR, de Aguilar MTP (2016) Influence of reburning on the pozolanicity of sugar-cane bagasse ashes with different characteristics. In: Materials science forum, vol. 869, Trans Tech Publications, Ltd., pp 141-146. https://doi.org/10.4028/www.scientific.net/ msf.869.141

47. Bahurudeen A, Wani K, Basit MA, Santhanam M (2015) Assesment of pozzolanic performance of sugarcane bagasse ash. $J$ Mater Civ Eng 28(2):04015095

48. Bish DL, Post JE (1988) Modern powder diffraction-reviews in mineralogy. J Appl Cryst 21:86-91

49. EN15167-1:2006 Ground granulated blast furnace slag for use in concrete, mortar and grout. Definitions, specifications and conformity criteria

50. ASTM C618-05 (2005) Standard specification for coal fly ash and raw or calcined natural pozzolan for use in concrete. ASTM International, West Conshohocken

51. Tashima MM, Soriano L, Monzó J, Borrachero M, Akasaki JL, Payá J (2014) New method to assess the pozzolanic reactivity of mineral admixtures by means of $\mathrm{pH}$ and electrical conductivity measurements in lime: pozzolan suspensions. Materiales de Construcción 64(316):032

52. Moropoulou A, Bakolas M (2005) Strength development and lime reaction in mortar for repairing historic masonries. Cem Concr Compos 27:289-294

53. Ríos-Parada V, Jiménez-Quero VG, Valdez-Tamez PL, MontesGarcía P (2017) Characterization and use of an untreated 
Mexican sugarcane bagasse ash as supplementary material for the preparation of ternary concretes. Constr Build Mater 157:83-95

54. Souza LMSd, Fairbairn EdMR, Toledo-Filho RD, Cordeiro GC (2014) Influence of initial $\mathrm{CaO} / \mathrm{SiO}_{2}$ ratio on the hydration of rice husk ash- $\mathrm{Ca}(\mathrm{OH})_{2}$ and sugar cane bagasse ash- $\mathrm{Ca}(\mathrm{OH})_{2}$ pastes. Quim Nova 37(10):1600-1605

55. Pereira A, Akasaki JL, Melges JL, Tashima MM, Soriano L, Borrachero MV, Monzó J, Payá J (2015) Mechanical and durability properties of alkali-activated mortar based on sugarcane bagasse ash and blast furnace slag. Ceram Int 41(10):13012-13024

Publisher's Note Springer Nature remains neutral with regard to jurisdictional claims in published maps and institutional affiliations. 